\title{
Survey The Relationship Between Personality Characteristic and Anti-Productivity Behaviors (Case Study: Employees of West Mazandaran Electricity Distribution Company)
}

\author{
Mohammad Rezanezhad ${ }^{1}$
}

${ }^{1}$ Ph.D. Student of Public Administration - Organizational Behavior, Faculty of Management and Accounting, Islamic Azad University of Chalus Branch, m.rezanezhad.sarga@gmail.com

\begin{tabular}{|c|c|}
\hline ARTICLE INFO & ABSTRACT \\
\hline $\begin{array}{l}\text { Keywords: } \\
\text { Abnormal Work } \\
\text { Behaviors } \\
\text { Anti-Productivity } \\
\text { Personality Traits }\end{array}$ & $\begin{array}{l}\text { Abnormal behavior is a kind of voluntary behavior that violates organizational } \\
\text { norms and reduces the productivity of organizations and individuals. This } \\
\text { behavior involves abusive behaviors, production diversion behaviors, sabotage or } \\
\text { sabotage, theft, and neglected or retarded behaviors (Hadizadeh et al., 2014). } \\
\text { Surveys show that the counterproductive behavior is a common and costly } \\
\text { problem for many organizations. Probably one of the factors associated with these } \\
\text { behaviors is personality. Therefore, the main goal of this study is to investigate } \\
\text { the relationship between personality traits and anti-productivity behaviors (Rabie } \\
\text { and Babadi, 1394). The research method was descriptive and correlational. The } \\
\text { society consisted of the official employees of West Mazandaran Electricity } \\
\text { Distribution Company, which } 69 \text { people were selected by Morgan's method. In } \\
\text { this research, } 60 \text { questionnaires of the Five Factors Questionnaire (NEO) } \\
\text { Questionnaire and Bent \& Robinson Standard Questionnaire (1975) were used. } \\
\text { The results of this study showed that there is a relationship between the five } \\
\text { factors of personality and anti-productivity behavior in West Mazandaran } \\
\text { Electricity Distribution Company. }\end{array}$ \\
\hline
\end{tabular}

\section{Introduction}

Skilled and efficient human resources are considered to be the most important capital of any organization. Human factors play a role more than other factors in improving the performance and fulfillment of missions of an organization. Human resources with the most important factor of production are the most important capital and the main source of competitive advantage and create the basic capabilities and real wealth of each organization. Therefore, investing in identifying talents, selecting and employing deserving human resources at different levels of organizational occupation, performance monitoring, skill development, effective policy implementation, and the proper conduct of human resources are essential. Also, counterproductive behaviors are a set of tangible behaviors Which damages the organization or its members (Masoumi and BanjhShafiee, 1393). Most of the previous researches on antiproductivity behaviors was based on certain behaviors such as theft or invasion. For example, an obsessive employee is trying to harm the company in which he or she works and wants to do this by stealing or destroying his equipment. Therefore, in this research, considering personal characteristics and anti-productivity behaviors, we will interact with them.

Today, in organizations and between personality traits and employees, there are some views that can be traced briefly to examples of anti-productivity behavior. The ethical characteristics of individuals play an important role in their performance. Some of these points are briefly outlined in this section: A legal employee of a company can complete their tasks by eliminating 
the time spent on computer games and web browsing. "I do not think working is necessary to the extent that the director expects, even if I can do it," he says (Farrokh Seresht, 2011).

"It does not matter to me, I'll retire a few more years," said a worker at a car manufacturing plant that does his work slowly and does not have any job. So I'm coming later and leaving my job sooner. What can they do? There is nothing in most cases right. "I think if I have two hours of useful work a day, I'd deserve to have a short time," says the manager of the recruitment of a company that works hard at work and who likes and does his job well.

\section{Theoretical Foundations of Research}

Anti-productivity work practices have a lot of economic, social and psychological costs for the organization. For example, a research has shown that roughly $5 \%$ of American organizations have been targeted at theft, employee fraud (Case, 2000). These behaviors cost an estimated $\$$ 50 billion a year to the United States, and the results showed that the causes of failure of $20 \%$ of the organization were such behaviors (Cuffin, 2003). In addition to these costs, abnormal work behaviors also have negative psychological effects, such as negative consequences on mental and physical health, decreased staff morale, increased absenteeism and displacement, decreased self-esteem and increased stress (Hool et al., 2003: Genghik, Bowling \& Bair, 2006: O'Learie et al 1996: Griffin 1998). Generally, in addition to the direct costs resulting from abnormal work behaviors, indirect costs such as loss of organizational reputation and even the loss of client organizations result from these behaviors.

Unfortunately, despite the considerable costs and disadvantages caused by abnormal work behaviors, these behaviors are still remarkably widespread. Based on research, 33 to 75 percent of employees are at least one of the forms of abnormal work behaviors (Harper, 1990). More striking is the fact that many deviant behaviors are not recognized by the staff, which makes the abnormal work patterns of the abnormal work patterns unattainable (Congressional Evaluation Office, 1990).

\section{Conceptual model:}

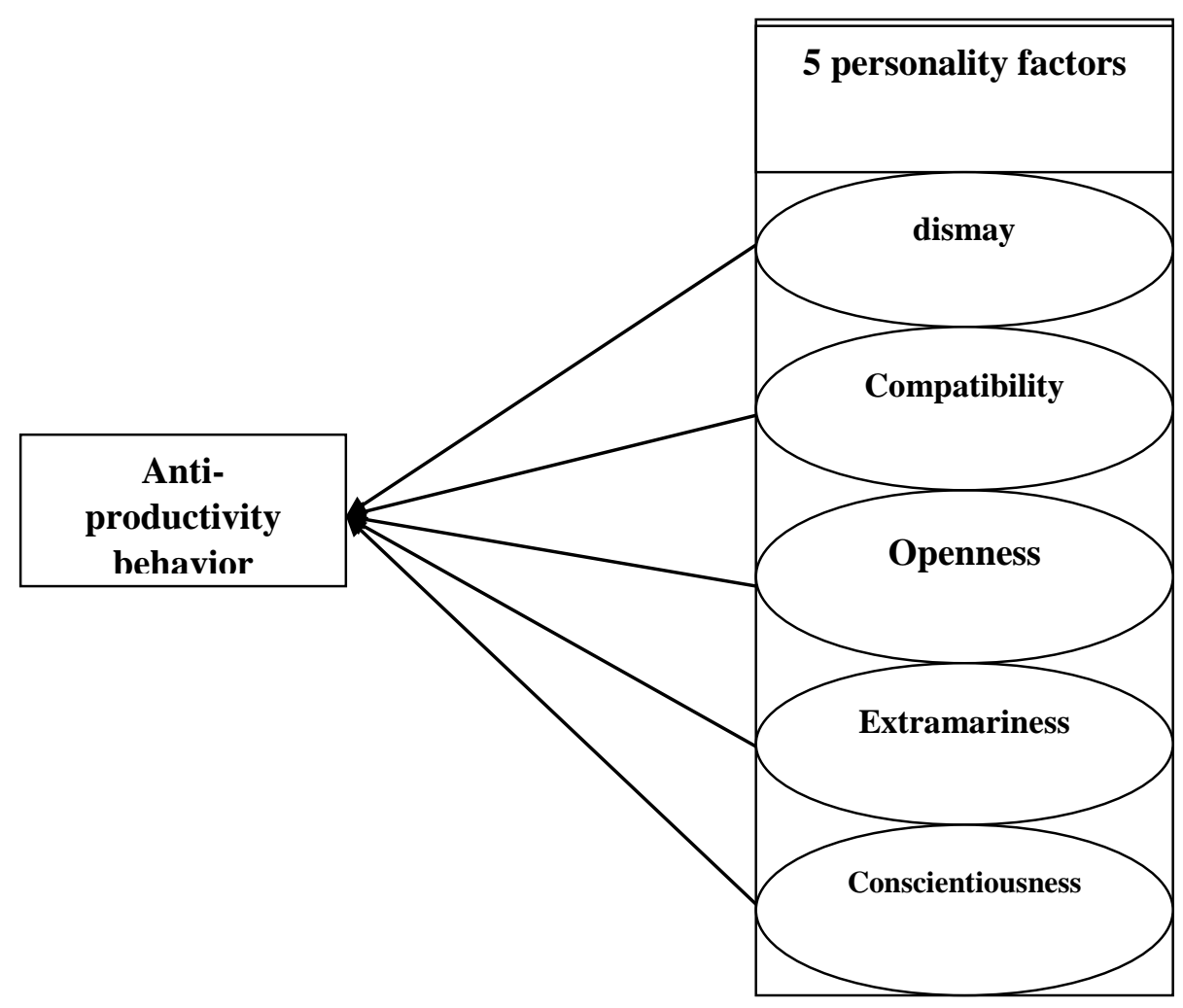

Standard model of (NEO) \& Bent Robinson (1975) 


\section{Abnormal Behavior}

Robinson \& Bennett (1995) defined an abnormal behavior in the organizational domain as the voluntary behavior of members of an organization that violates organizational norms and threatens organizational performance or its members with such actions. (Rattendo and Sakit, 2002) reported three classes of occupational behaviors that affect overall job performance: task behaviors, civic behaviors, and anti-productivity behaviors. Of these three areas, less attention has been paid to anti-productivity behaviors. Three studies have been identified by examining studies to identify the causes of distortion in the workplace or the antiproliferation behavior. The first trend refers to studies that regard anti-productivity behaviors as a reaction to the business environment. Followed by trends suggest that counterproductive behaviors in the workplace have resulted in employees reacting to negative workplace experiences such as disastrous job stresses (Chen and Spector, 1993) perceived injustice (Greenberg, 1993), experience of disability and feeling Shame (Polson, 2001). The second trend in studies of causes of antiproliferation behaviors suggests these behaviors reflect the personality of the individual. Characteristic features such as the five major personality dimensions (Henle, 2005), socialization and impulsivity (Henle, 2005). The place of anxiety and trait anxiety (Spector and Fox, 2002) have been investigated as the basis for these behaviors (Bennett \& Robinson, 2003). The third trend in the research, which involves antiproliferation behavior, is to regard these behaviors as a form of adaptation to the social fabric. Although defining antiproliferation behaviors is a kind of deviation from acceptable organizational norms, there may be some social pressures in the workplace that support deviations from the organization's desirable norms and cause the committing of anti-productivity behaviors as a kind of value (Bennett \& Robinson, 2003).

In this research, the second trend is investigated and the understanding of the individual's behavior begins with the study of the role of psychology in organizational behavior (Robbins, 1943). Personality characteristics are related to the way people perceive work justice in the workplace (Monty Lys and Johnson, 2006). Perceptions from different aspects of the workplace through personality variables affects the incidence of antiproliferation behaviors and the importance of personality as a major factor in the direction of behavior on the other, seeking to answer the question of whether the major personality features affect the appearance of malicious behaviors or not? looks like important. Therefore, the present study seeks to investigate the relationship between personality traits and anti-productivity behaviors in the workplace.

Personality: A personality is a concept that is used both in folk and in action. Basically, everyone has a unique character, ability, and features that show behavioral patterns, responses and reactions to the inner and outer environment that shape these personality traits. The personality of the human being has always been the subject of attention and attracted the attention of many scholars and experts. The word root is the equivalent of the word "personality" or "personit'e" of France, and in fact derived from the Latin persona, which means a mask in the ancient Greek and Roman cast of theater actors (Karimi, 2007).

Several major theorists have given definitions of personality. Gordon Allport (1937), the founder of modern character studies and defines personality as: a dynamic organization of the psychoanalytic systems that determines his specific behaviors and thoughts. Character is a unique pattern of personality traits (Gilford, 1952). The person can predict what the individual will do in a particular situation (Cattel, 1950). In general, it can be said that personality is the unique dimension of a person that distinguishes him from others, and only some of the components of this dimension are observable and examined through behaviors, actions, attitudes, etc. (Karimi , 1386).

Extroversion: One of the success factors of managers is their ability to communicate in human relationships. The most important aspect of working with humans is to establish human relationships with them. On the other hand, human communication skills are influenced by 
several factors including personality traits. In other words, people who call extrovert psychology can have a stronger human skill and, consequently, effective human relationships can improve manager performance (Roberts et al., 2005).

Conscientiousness: Conscience as a personality trait implies hardiness, order, accuracy, perseverance and accountability (Barrick \& Mount, 1991).

Emotional stability:

Emotional stability means the ability to control the emotions and to be rational. Therefore, those forces with an emotional stability are likely to be more successful in their decision making (Sanders, 2008).

Compatibility: This feature is described as being loved or accepted by others. People who have this feature are described as literate, flexible, trustworthy, good-natured, collaborative, tolerant, and well-mannered (Sanders, 2008).

Experiencing: People with this feature are imaginative, curious, open minded and artistically sensitive. Experimentalism has a high intelligence relationship. Experienced ones have a questionable mind, while those with low experience cannot accept new experiences.

\section{Research Methodology}

This research is descriptive and survey research. The research population consisted of the official employees of Mazandaran Electricity Distribution Company, numbering 300 people. The sample of the study was Morgan's sample with size of 169 people. The tools used in this study are the Five Personality Characteristics (NEO) and the Bennett \& Robinson AntiProductivity Test (1975). Validity of the questionnaire is content validity. In addition, both standard questionnaires are valid and their validity has been confirmed. To determine the reliability of Cronbach's alpha, the number is 0.982 . Descriptive and inferential statistics were used to analyze the data.

It should be noted that the statistical analysis of this research is done by SPSS software. In this research, after extracting the data and information collected and analyzing them, the explanation of the hypotheses through the implementation of Cronbach's alpha test to determine the reliability questionnaire, Kolmogorov-Smirnov test for normal and abnormal distribution of data, Spearman correlation test was used to determine the relation of nonparametric data. Friedman test has been used to rank the components.

\section{Findings}

First sub-hypothesis: There is a relationship between maladaptation and anti-productivity behavior in West Power Distribution Company of Mazandaran province. In the two-to-two test, there is a significance level of less than 0.05 between psychosis and antimicrobial behavior, which indicates that these two factors are correlated with each other. As how Spearman correlation is expressed, it can be seen that the correlation of the variables with each other is also high.

Table 1. Spearman Correlation Coefficient

\begin{tabular}{|c|c|}
\hline $\begin{array}{c}\text { Anti-productivity } \\
\text { behaviors }\end{array}$ & \multicolumn{1}{|c|}{ Factors } \\
\hline $0 / 245^{* *}$ & The correlation \\
$0 / 000$ & coefficient \\
169 & $\begin{array}{c}\text { Meaningful level } \\
\text { Number }\end{array}$ \\
\hline
\end{tabular}

Second sub-hypothesis: There is a correlation between compatibility and anti-productivity behavior in West Power Distribution Company of Mazandaran province. In two-to-two measurements between adaptability and anti-avoidance behavior, the significance level is less than 0.05, which indicates that these two factors are correlated with each other. As how Spearman correlation is expressed, it can be seen that the correlation of the variables with each other is also high. 
Table 2. Spearman Compatibility Correlation Coefficient

\begin{tabular}{|c|cc|}
\hline $\begin{array}{c}\text { Anti-productivity } \\
\text { behaviors }\end{array}$ & \multicolumn{2}{|c|}{ Factors } \\
\hline $0 / 409 * *$ & The correlation & \\
$0 / 000$ & coefficient & Compatibility \\
169 & Meaningful level & Number \\
\hline
\end{tabular}

Third sub-hypothesis: There is a relationship between openness and anti-productivity behavior in West Power Distribution Company of Mazandaran province. Spearman's correlation coefficient test shows the correlation between different nonparametric variables. To confirm or reject the correlation and the relationship between the variables of the research, there is a need for correlation tests to show that the research variables are correlated or independent of each other. In the two-to-two test, the openness and anti-profit behavior of the significance level are less than 0.05 , indicating that these two factors are correlated with each other. As how Spearman correlation is expressed, it can be seen that the correlation of the variables with each other is also high.

Table 3. Spearman correlation coefficient of openness

\begin{tabular}{|c|cc|}
\hline $\begin{array}{c}\text { Anti- } \\
\text { productivity } \\
\text { behaviors }\end{array}$ & Factors & \\
\hline $0 / 412^{* *}$ & The correlation & Openness \\
$0 / 000$ & coefficient & Meaningful level \\
169 & Number & \\
\hline
\end{tabular}

The fourth sub-hypothesis: There is a relationship between extramariness and anti-productivity behavior of the power distribution company in West of Mazandaran province. Spearman's correlation coefficient test shows the correlation between different nonparametric variables. To confirm or reject the correlation and the relationship between the variables of the research, there is a need for correlation tests to show that the research variables are correlated or independent of each other. In the two-to-two measure between outsourcing and the antiproductivity behavior of the meaningful level, it is more than 0.05 , which indicates that these two factors are not correlated.

Table4. Spearman Extramariness Correlation Coefficient

\begin{tabular}{|c|cc|}
\hline $\begin{array}{c}\text { Anti-productivity } \\
\text { behaviors }\end{array}$ & \multicolumn{2}{|c|}{ Factors } \\
\hline $0 / 033$ & $\begin{array}{c}\text { The correlation } \\
\text { coefficient } \\
\text { Meaningful level } \\
\text { Number }\end{array}$ & \\
169 & Extramariness \\
\hline
\end{tabular}

Fifth sub-hypothesis: There is a relationship between conscientiousness and anti-productivity behavior in West Power Distribution Company of Mazandaran province. Spearman's correlation coefficient test shows the correlation between different nonparametric variables. To confirm or reject the correlation and the relationship between the variables of the research, there is a need for correlation tests to show that the research variables are correlated or independent of each other. In measuring the two-to-two conscientiousness, and the anti-profit behavior of the meaningful level, it is less than 0.05 , which indicates that these two factors are 
correlated with each other. As how Spearman correlation is expressed, it can be seen that the correlation of the variables with each other is also high.

Table 5. Spearman Correlation coefficient of Conscientiousness

\begin{tabular}{|c|cc|}
\hline $\begin{array}{c}\text { Anti-productivity } \\
\text { behaviors }\end{array}$ & \multicolumn{2}{|c|}{ Factors } \\
\hline $0 / 511^{* *}$ & The correlation & \\
$0 / 000$ & coefficient & Conscientiousness \\
169 & $\begin{array}{c}\text { Meaningful level } \\
\text { Number }\end{array}$ & \\
\hline
\end{tabular}

\section{Friedman test and variables ranking}

In this section, the ranking of the variable "5 personality factors" is evaluated from its subfactors

Table 6. Friedman Test

\begin{tabular}{|c|c|}
\hline rate & variable \\
\hline $2 / 61$ & Dismay \\
\hline $2 / 02$ & Extramariness \\
\hline $1 / 38$ & Openness \\
\hline $1 / 31$ & Conscientiousness \\
\hline $1 / 22$ & Compatibility \\
\hline
\end{tabular}

According to the data presented in Table 6, the result is that, for the sample population, the psychosocial factor with a score of 2.61 is most important. Afterwards, the factors of extramariness, openness, conscientiousness, and consistency are next ranked.

Table 7. Significance level of Friedman test

\begin{tabular}{|c|c|}
\hline point & Coefficient \\
\hline 70 & Number \\
\hline $630 / 111$ & Chi square \\
\hline 4 & Degree of freedom (df) \\
\hline $000 / 0$ & Significance level (Sig) \\
\hline
\end{tabular}

Considering the level of significance (0.000) which is obtained in Table 7, and since the significance level is below 0.05 , it indicates that the factors are not of the same rank.

\section{Discussion and Conclusion}

The present study was conducted to investigate the relationship between personality traits and anti-attitude behaviors. The results of this study are as follows: There is a significant relationship between personality dimensions and anti-productivity behavior. In the first dimension, there is a significant relationship between mental disorder and anti-repression behavior. According to this relationship and a questionnaire distributed among the official employees of Mazandaran Electric Power Distribution Company, it is recommended that the managers of the company reduce the stress on work and create an environment in which the employees feel joy and vitality so that the conflict and tension between them are greatly reduced and brought a secure and trusted space for them. In the second dimension, it was found that there is a significant relationship between adaptation and anti-productivity behavior. Therefore, it is suggested that managers of West Electricity Distribution Company of Mazandaran should be intimate and friendly in order to make the work environment more 
coherent and friendly, and to connect the relationship between the president and the prosecutor. They can, by creating a suitable environment for the employees, commit them to pick up the affairs in openness, it was also found that there is a significant relationship between it and antiproductivity behavior. Managers of Mazandaran Electricity Distribution Company are encouraged to work in a clean and healthy atmosphere for employees, and can even motivate employees by taking amusement and entertainment programs into their non-administrative hours. In the aspect of extinction, it was found that there is a significant relationship between it and anti-productivity behavior. It is suggested to managers of Mazandaran Electricity Distribution Company to create an appropriate mechanism for obtaining logical comments and constructive criticisms of employees. In the dimension of conscientiousness, there was a significant relationship between conscientiousness and anti-productivity behavior. It is suggested to managers of Mazandaran Electricity Distribution Company to stimulate their work conscience by creating a sense of responsiveness.

In general, managers of West Electricity Distribution Company of Mazandaran are recommended to put the rest and cleanliness and the warm and friendly environment of good morals and the proximity of the managers to the employees in the working environment so that they can deal with such problems as lack of work and tilting of the mouth, to prevent the employees' ethics and non-commitment to the organization and to use all the potential of the staff to best serve the goals of the organization.

\section{References}

Bennett R.J. \& Robinson S. L. (2003). The past present and future of workplace deviance research. In J. Greenberg (ed.). Organizational behavior: The state of the science (2nd ed., Pp. 247-281). Mahwah NJ: Erlbaum.

Bennett R. J. \& Robinson. S. L. (2003). The past present and future of workplace deviance research. Jerry Greenberg (ed.) Organizational Behavior. The State of the Science. 2ndUpdated 2/2013 edition.

Bowling N. A. \& T.A. Beehr (2006). Workplace harassment from the victim's sperspective: A theoretical model and meta-analysis. Journal of Applied Psychology. 91. pp.998-1012.

Chen P. Y. \& Spector. P. E. (1992). Relationships of work stressors with aggression. withdrawal Theft and substance use: Anexploratory study. Journal of Occupational and Organizational Psychology. 65. 177-184 cooperation. European Journal of Personality. 22. 519-539. Greenberg J. (1990). Employee theft as a reaction to underpayment inequity: The hidden cost of pay cuts. Journal of Applied Psychology. 75. 561-568.

Coffin B. (2003). Breaking the Silence on White Collar Crime. Risk Management. (50).p.8

Farrokh Sersht, Behzad, (2011), Investigating the Components Affecting the Anti-Production Factors, National Conference on Entrepreneurship, Mashhad

Griffin R. W.; A.M.O'Leary\&J.Collins (1998). Dysfunctional Work Behaviors in Organizations. In Cooper C. L. \& Rousseau DM (eds.). Trends in OrganizationalBehavior (pp. 65-82). New York NY: John Wiley \& Sons.

Hadizadeh, Akram and Rezaian, Ali and Tabarsa, Gholamali and RaminMehr, Hamid, The presentation of anomalous behavioral behavior management model based on the theory of planned behavior, Oct. 93.

Harper. D. (1990). Spot light abuse-save profits. Industrial Distribution. 79. October 1. pp.47-51.

10- Henle A. C. (2005). Predicting workplace deviance from the interaction between organizational sensation and personality. Journal of Manageria Issues. 17 (2). 247-163. 
Hoe H., S. Einarsen\&C.Cooper (2003). Organizational effects of bullying. In Einarsen S. Hoel H. Zapf D. Cooper C (Eds.). Bullying and emotional abuse in the workplace: International perspectives on research and practice. London: Taylor \& Francis.

Keashly L. \& K. Jagatic. (2003). By any other name: American perspectives on workplace bullying. In S. Einarsen. H. Hoel. D. Zapf. \& C. Cooper (eds.)

Masoumi, Hasan and Banej Shafiei (1393), The Effect of Personality Factors on Productivity, 5th International Management and Accounting Conference, Tehran

O'Leary-Kelly A.M.; R.W.Griffin\& D.J. Glew (1996). Organization-Motivated Aggression: A Research Framework. Academy of Management Review. 21. (1) .pp. 225-253

Rabiei, Mohammad and Babadi, Faceshare, Anti-Productivity Behaviors and its Relationship with Five Personality Characteristics, March 1994.

Robinson. S. L. \& R. J. Bennett. (1995). A typology of deviant workplace behaviours. A multidimensional scaling study. Academy of Management Journal. 38 (2). pp. 555-572. http://dx.doi.org/10.2307/256693.

Rotundo. M. \&Sackett. P. R. (2002). The relative importance of the task. citizenship and counterproductive performance to global job performance ratings: A policy capturing approach. Journal of Applied Psychology. 87. 66-80.

Spector. P. E. \& Fox S. (2002). An emotion-centered model of voluntary work behavior: Some parallels between counterproductive work behavior and organizational citizenship behavior. Human Resource Management Review. 12269292. 